\title{
QBO influences on the variability of planetary waves in the equatorial mesopause region
}

\author{
S. Sridharan ${ }^{1}$, S. Gurubaran ${ }^{1}$, and R. Rajaram ${ }^{1,2}$ \\ ${ }^{1}$ Equatorial Geophysical Research Laboratory, Indian Institute of Geomagnetism, Krishnapuram, Tirunelveli 627 011, India \\ ${ }^{2}$ Indian Institute of Geomagnetism, Panvel, Navi Mumbai 410 218, India
}

(Received April 10, 2003; Revised October 9, 2003; Accepted December 22, 2003)

\begin{abstract}
MF radar observations of hourly mean zonal and meridional winds at $86 \mathrm{~km}$ over Tirunelveli $\left(8.7^{\circ} \mathrm{N}, 77.8^{\circ} \mathrm{E}\right)$, India, over a period of five years (1993-1997) are utilized to study the possible influence of stratospheric quasibiennial oscillation (QBO) on the vertical propagation of planetary-scale waves. The radiosonde winds at Singapore are used to identify the phase of the stratospheric QBO at $30 \mathrm{hPa}$. The study reflects that the interannual variability of the planetary waves may be explained partly by the direction of the stratospheric QBO winds. Limitations of the present work are: (i) the QBO cycles considered are not many and (ii) the observed waves are presumed to originate from below and propagate through the stratospheric QBO wind system.
\end{abstract}

Key words: QBO, planetary waves, mesosphere, MLT region, semi-annual oscillation, wave-mean flow interaction.

\section{Introduction}

The zonal mean circulation in the equatorial and lowlatitude middle atmosphere is characterized by quasibiennial oscillation (QBO) with an average periodicity of nearly 28 months that dominates in the lower stratosphere (Wallace and Kousky, 1968) and semiannual oscillation (SAO) with a periodicity of nearly six months, that dominates in the upper stratosphere and lower mesosphere and in the mesopause region (Hamilton, 1982; Vincent, 1993; Tsuda et al., 1995; Burrage et al., 1996, to state a few). In the lower stratosphere, the existence of QBO is mainly due to the vertical transfer of momentum by gravity waves (Dunkerton, 1997), though the observed amplitudes of equatorial waves, namely, Kelvin and Rossby-gravity waves, may be sufficient to drive a QBO in idealized models of the atmosphere (Holton and Lindzen, 1972; Plumb and McEwan, 1978). The SAO is mainly driven by gravity waves, with some contribution to its eastward phase from Kelvin waves (Dunkerton, 1982).

The stratopause and mesopause SAO winds are nearly out of phase with each other (Hirota, 1978). The stratopause (mesospause) SAO shows eastward maxima at the equinoxes (solstices) and westward maxima at the solstices (equinoxes). Dunkerton (1982) suggested that the gravity-wave transmittivity through the stratopause region would be strongly modulated by the presence of the SAO to cause the observed out-of-phase relation between the stratopause and mesopause oscillations.

The SAO has some of the characteristics in common with the QBO. Both QBO and SAO are equatorially confined with a half width of about $25^{\circ}$ latitude. Both are generated by flux convergence of upward propagating waves. The down-

Copy right(C) The Society of Geomagnetism and Earth, Planetary and Space Sciences (SGEPSS); The Seismological Society of Japan; The Volcanological Society of Japan; The Geodetic Society of Japan; The Japanese Society for Planetary Sciences. ward propagation is shown by both oscillations, however, it is limited only to the eastward phase of the stratospheric SAO (Andrews et al., 1987). Recent satellite and radar observations bring out the presence of interannual variability of westward phase of mesopause SAO (MSAO) occurring during spring equinox (Burrage et al., 1996; Rajaram and Gurubaran, 1998). There has been found an apparent interannual modulation of the westward phase of the MSAO (sometimes termed as 'mesospheric QBO') by the stratospheric QBO. It has been suggested that the mesospheric SAO could be modulated by the westward phase of stratospheric QBO (Burrage et al., 1996) and that the apparent modulation comes through selective damping of the spectrum of vertically propagating waves forced by deep convection in the tropics. Mayr et al. (1997), through simulations with a global scale spectral model, suggested that the 'mesospheric QBO' could be driven by selective filtering of smallscale gravity waves by the underlying winds through which they propagate. Garcia et al. (1997) supported the plausibility of gravity wave filtering effects in interpreting the observed interannual variability of the MSAO. The simulation of Garcia and Sassi (1999) attempted to justify the role of planetary and intermediate-scale waves (zonal wavenumbers 5-25) by forcing them with plausible estimates of unsteady convective heating. However, the observational confirmation for the existence of these waves is lacking.

Besides SAO in zonal wind, the tides and planetary-scale waves observed in the mesosphere and lower thermosphere (MLT) region also undergo strong interannual variability (Vincent et al., 1998; Gurubaran and Rajaram, 1999; Gurubaran et al., 2001). It may be due to the interannual variability of either wave excitation mechanisms or background winds through which they propagate. The stratospheric QBO winds selectively control the upward propagation of those waves that have their origin in the lower atmosphere depending on their phase velocity. Hagan et al. (1999) investigated 
Monthly mean zonal wind over Tirunelveli (contour interval: $10 \mathrm{~m} / \mathrm{s}$ )
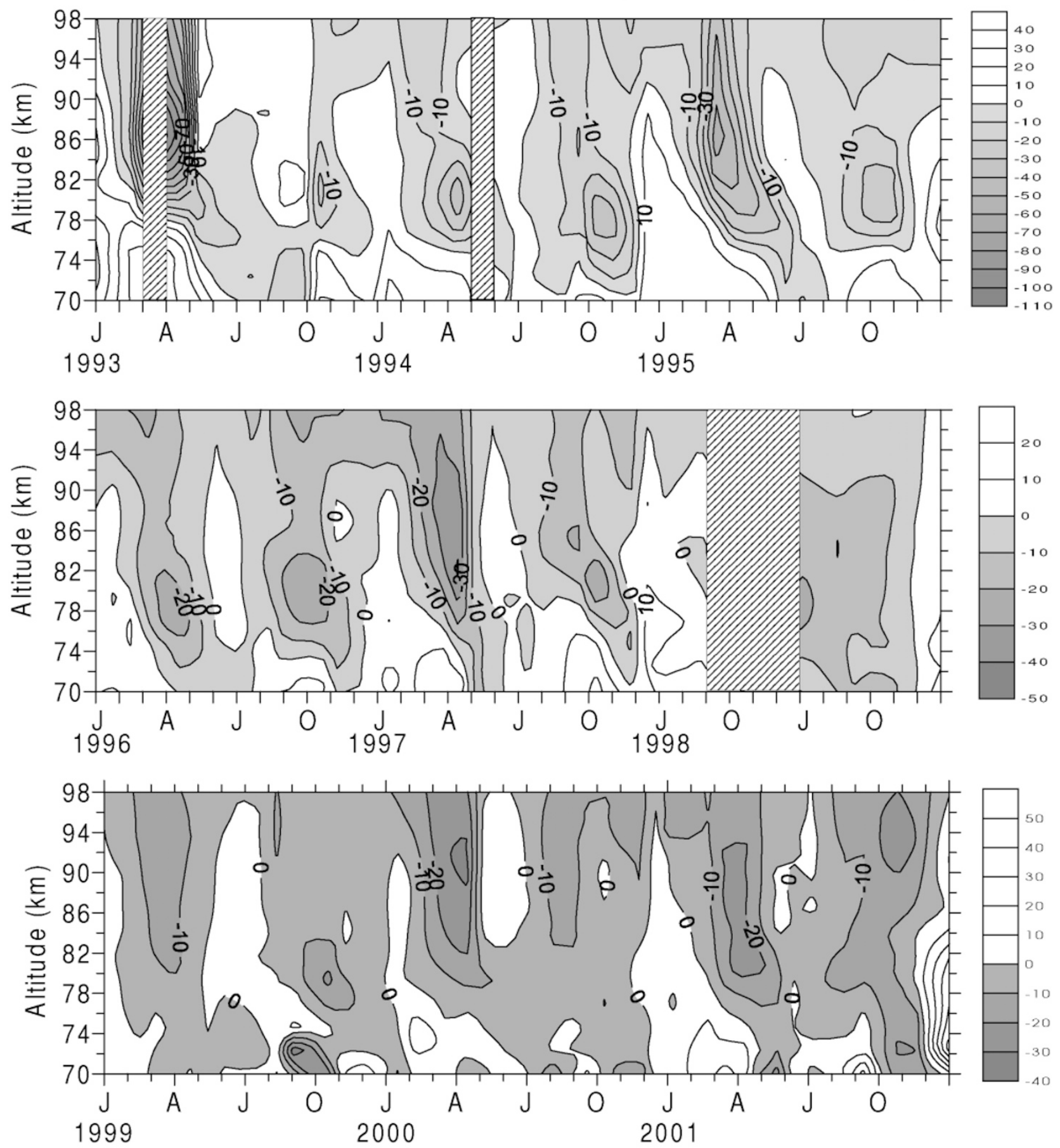

Month number (1993-2001)

Fig. 1. Time-height cross-sections of monthly mean zonal wind over Tirunelveli for the altitude region 70-98 km and for the years $1993-2001$.

the effects of the stratospheric QBO on the migrating diurnal tide based on numerical experiments conducted with the global scale wave model. The diurnal tidal response was found to be significantly affected by the QBO in zonal mean zonal winds, but largely insensitive to the QBO in stratospheric ozone.

In this paper, the possible influence of stratospheric QBO on the vertical propagation of planetary waves to MLT region is examined using the wind data obtained by medium frequency radar at Tirunelveli during the years 1993-1997. The stratospheric QBO is inferred from the monthly mean stratospheric wind measurements at $30 \mathrm{hPa}$ level obtained by radiosondes at Singapore. It is presumed that the waves examined in this work originate below the stratosphere. As they propagate through the stratospheric QBO, they interact with the background wind. Those waves having phase speeds exceeding the QBO wind speeds and those having propagation direction opposite to the direction of the QBO phase escape to mesospheric heights. In the latter region the waves interact with the dominant wind system, namely, the mesopause 


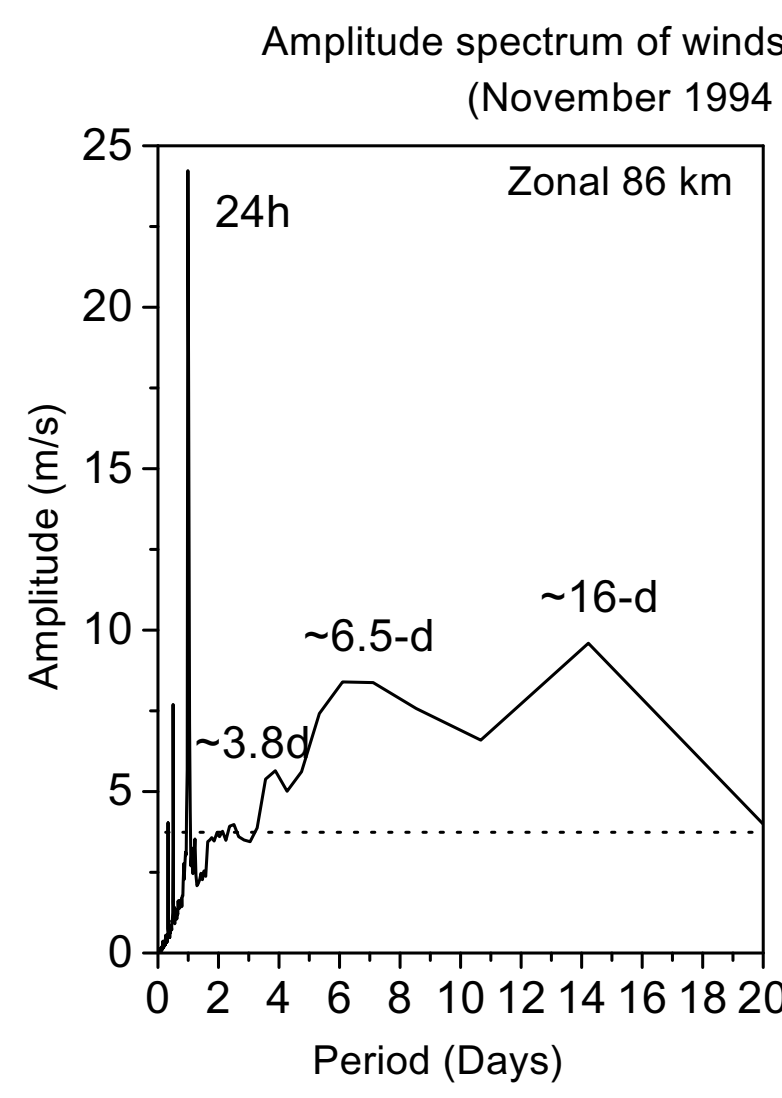

over Tirunelveli $\left(8.7^{\circ} \mathrm{N}, 77.8^{\circ} \mathrm{E}\right)$

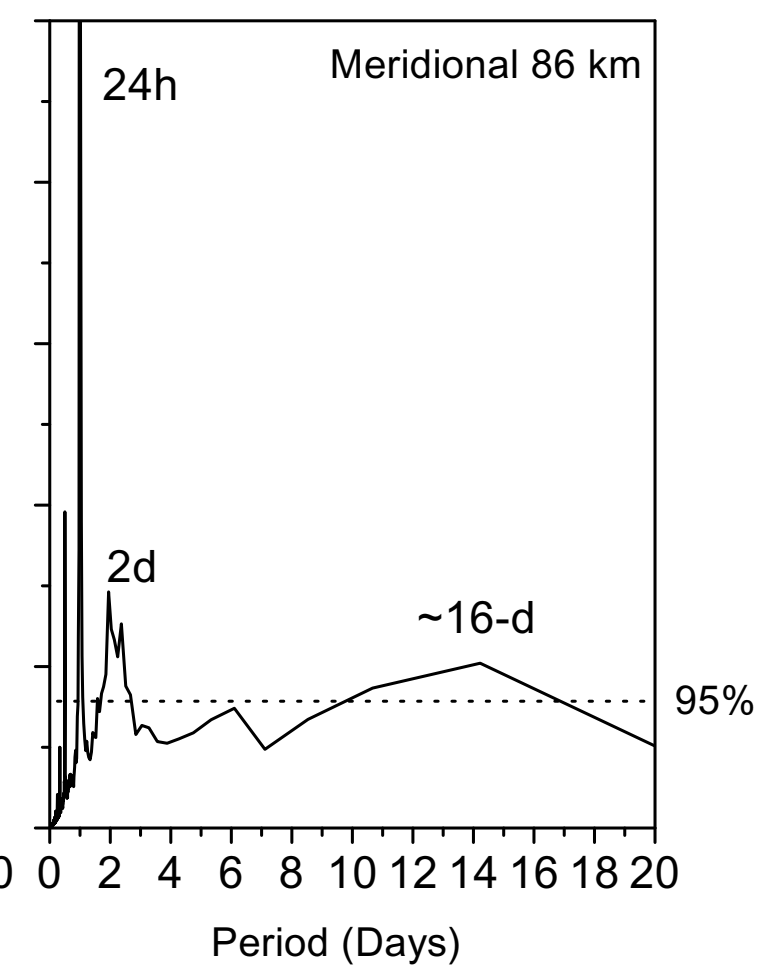

Fig. 2. Amplitude Spectrum of zonal and meridional winds at $86 \mathrm{~km}$.

semi-annual oscillation. The discussion of the results presented herein is oriented towards examining these interactions at stratospheric QBO and MSAO levels. Though the analysis is qualitative in nature, the results highlight possible influences of stratospheric QBO and MSAO wind systems on the observed long-term variabilites of planetary-scale waves in the MLT region.

\section{Data Analysis}

The medium frequency radar operating at Tirunelveli $\left(8.7^{\circ} \mathrm{N}, 77.8^{\circ} \mathrm{E}\right)$ has been providing wind information in the altitude region of $68-98 \mathrm{~km}$ since the middle of 1992 . The system details, mode of operation and the method of wind determination are the same as described by Vincent and Lesicar (1991). Results on mean winds (Rajaram and Gurubaran, 1998), tidal climatologies (Gurubaran and Rajaram, 1999), and characteristics of quasi-2-day wave and 3.5-day ultra-fast Kelvin wave (Gurubaran et al., 2001; Sridharan et al., 2002) were reported earlier. The data acceptance rate is relatively high in the altitude region of $84-88 \mathrm{~km}(\mathrm{Ra}-$ jaram and Gurubaran, 1998) and therefore, the data from these heights are averaged, linearly interpolated to fill gaps and used to bring out the time-evolution of wave energy. The temporal variabilities of the wave energies are compared with the phase of stratospheric QBO at $30 \mathrm{hPa}$.

\section{Results and Discussion}

The time-height cross-sections of monthly mean zonal winds from 70-98 km for the years 1993-2001 is presented in the contour form in Fig. 1. Shaded portions of the con- tours represent westward flow regimes and unshaded portions represent eastward flow regimes. The blocks containing slashed lines show the intervals of missing data. There are a few data gaps in the months of May 1993, May 1994, and March-June 1998. As reported earlier (Rajaram and Gurubaran, 1998), the mean zonal wind in the mesospheric region over Tirunelveli shows a semi-annual oscillation (SAO) with westward flow during equinoxes and eastward flow during solstices. One can notice an interannual variability in the enhanced westward flow during the spring equinoxes near the mesopause region. Peak westward flows of $\sim 80 \mathrm{~m} / \mathrm{s}$, $\sim 55 \mathrm{~m} / \mathrm{s}$, and $\sim 40 \mathrm{~m} / \mathrm{s}$ are observed during 1993, 1995 and 1997 respectively. The flows are weaker during the equinox periods of 1994 and 1996. This feature is qualitatively identical to the one detected by Burrage et al. (1996) in data samples obtained from the UARS satellite and ground-based MF radar experiment conducted from Christmas Island. Apart from this signature, the maximum westward velocities in the present analysis are comparable in equinox and solstice months of the years 1999-2001 and hence there is no distinct interannual variability seen during those years.

The presence of dominant planetary-scale wave modes can be inferred from the power spectrum of measured wind components. The average spectra of the zonal and meridional winds derived from 35 months (November 1994-September 1997) of wind data are presented in Fig. 2. The spectra for zonal (solid line with circle) and meridional winds (dashed line with squares) are constructed by subdividing the time series into 2048-hour segments and averaging the power spectra computed for each segment. The zonal and meridional 


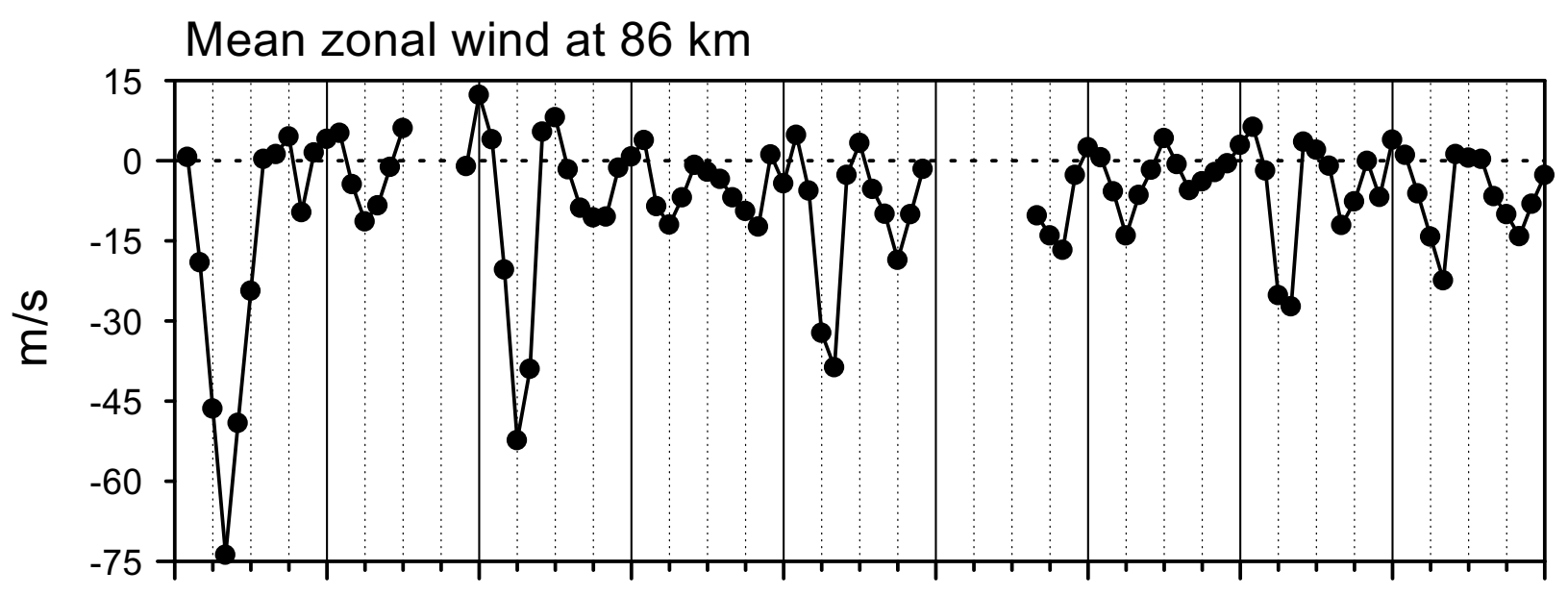

$\longrightarrow$ QBO in zonal wind at $86 \mathrm{~km}$

Singapore Radiosonde winds at $30 \mathrm{hPa}$

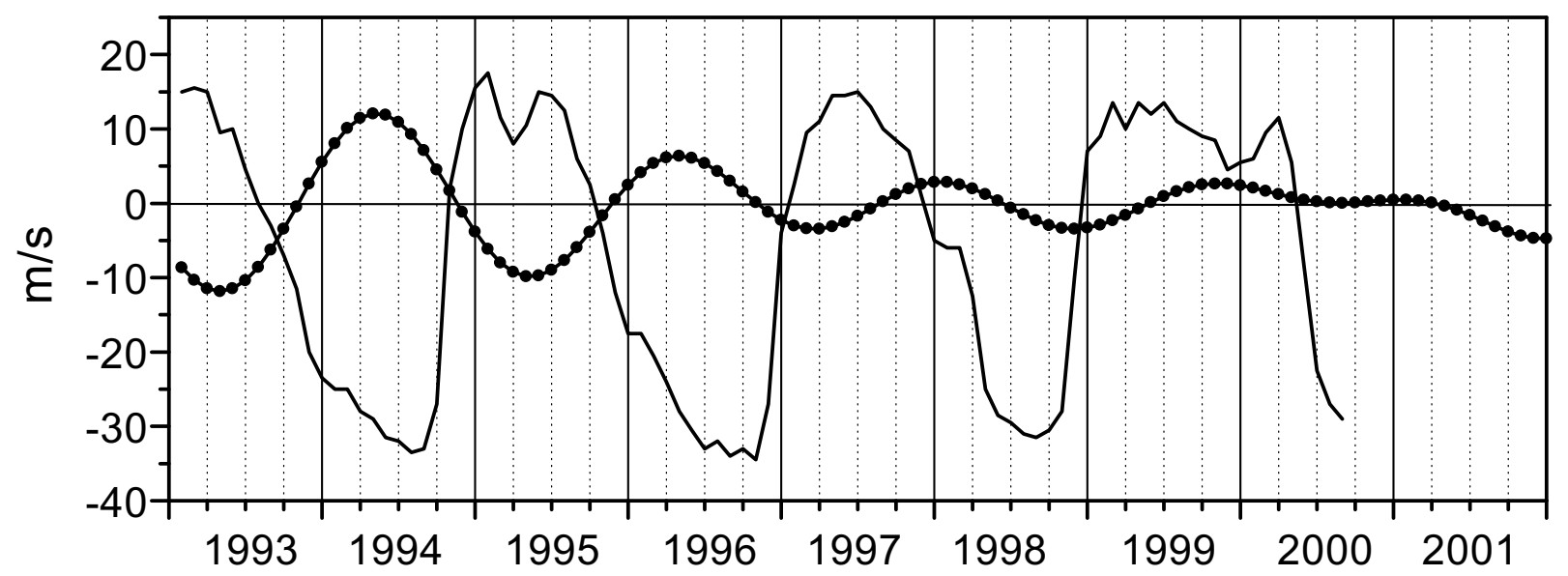

Fig. 3. Comparison of temporal variation of mean zonal wind at $86 \mathrm{~km}$ (top) and that of Singapore radiosonde winds at $30 \mathrm{hPa}$ (bottom) for the years 1993-2001.

winds data are high-pass filtered with a cut-off period of 20 days, before subjecting them to power spectrum analysis. The segments are overlapped by $25 \%$ in order to minimize the variance associated with each spectral estimate (Press et al., 1992). Spectra computed for three heights, namely, 84, 86 and $88 \mathrm{~km}$ are then averaged to further improve the spectral estimate. To test the statistical significance of the spectral amplitude $\left(R_{k}\right)$, we have used a method in which the probability ' $p$ ' that the ratio $R_{k}^{2} / \Sigma R_{k}^{2}$ exceeds a parameter ' $g$ ' is given by $p=\left[m(1-g)^{m-1}+\right.$ higher order terms $]$ (here, $\Sigma R_{k}^{2}=2 / N \Sigma\left(X_{i}-X_{\text {mean }}\right)^{2}$, the summation on the left hand side runs from $k=1$ to $m$ and that on the right hand side runs from $i=1, N$, the number of points; $m=N / 2$. The error introduced in neglecting the higher order terms is only $0.1 \%$ for $p=0.05$ (95\% confidence level). Therefore, the parameter $g$ (for $p=0.05$ ) can be calculated from the relationship, $p=m(1-g)^{m-1}$. The parameter $g_{k}$ is given by $g_{k}=R_{k}^{2} /\left\{(2 / N) \Sigma\left(X_{i}-X_{\text {mean }}\right)^{2}\right\}$. If $g_{k}>g_{p=0.05}$ (for $95 \%$ confidence level), the amplitude is $95 \%$ significant. The $95 \%$ confidence level is shown as dotted lines in the amplitude spectra of zonal and meridional winds (Fig. 2) to infer the significance of the peaks observed.

In Fig. 2 narrow spectral peaks associated with the diurnal
(24 hr), semi-diurnal (12 hr) and terdiurnal ( $8 \mathrm{hr})$ tides are clearly evident. The tides are observed to be more dominant in meridional wind than in zonal wind. Periods shorter than about 1 day are ascribed to gravity wave motions. There are also peaks with smaller amplitudes at periods longer than 24 hours. The broad peak with a period near two days in the meridional component is due to the $2-\mathrm{d}$ wave, which is a strong feature of the midlatitude summer mesosphere, particularly, in the southern hemisphere (Salby, 1981a, b; Harris, 1994; Palo et al., 1997). The zonal spectrum shows noticeable power in the period range between 3 and 10 days, with peaks near 3-4 days and 6-8 days. The former peaks denote the presence of 3.5-day wave, which is known to be an ultrafast Kelvin wave having a period varying between 3.0 and 3.8 days (Kovalam et al., 1999; Sridharan et al., 2002). The latter peaks denote the 6.5-day wave, which is a westward propagating disturbance (Meyer and Forbes, 1997), sometimes stronger in its energy than the diurnal tide as noted in a recent work of the authors (not published). Both spectra show peaks in the period range 12-20 days. However, the peaks in zonal wind spectrum are more enhanced than their meridional counterpart. They correspond to the 16day wave, which has been reported as being observed more 

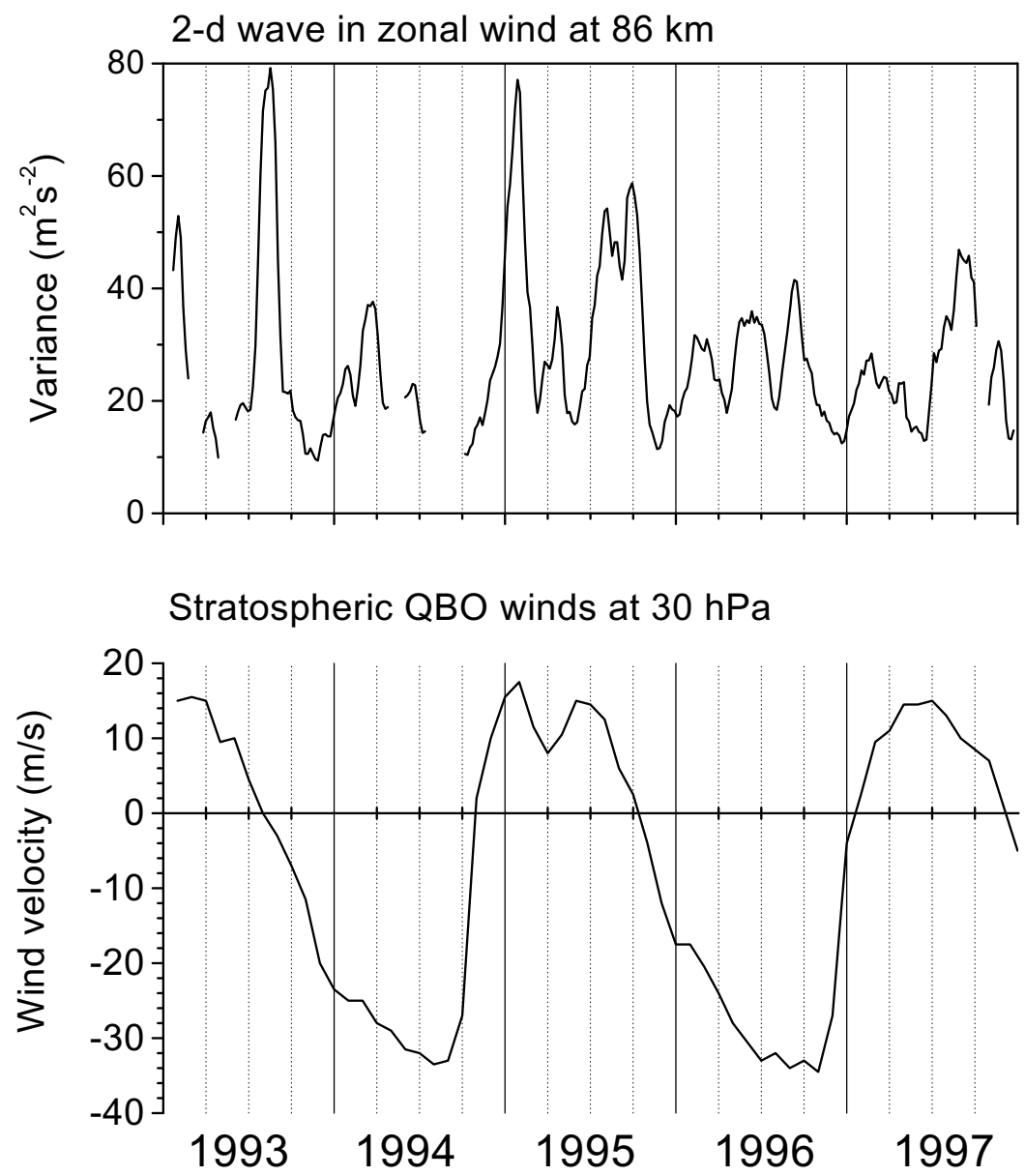

Fig. 4. Comparison of time-variance of 2-d wave in zonal wind at $86 \mathrm{~km}$ (top) and stratospheric QBO phase at $30 \mathrm{hPa}$ (bottom) for the years $1993-1997$.

frequently in winter (Manson and Meek, 1986). However, noticeable wave activity has also been observed in summer (Williams and Avery, 1992). The spectra for the zonal and meridional winds are very similar to those reported from other equatorial and low-latitude sites, namely, Christmas Island $\left(2^{\circ} \mathrm{N}, 157^{\circ} \mathrm{W}\right)$ and Pontianak $\left(0^{\circ} \mathrm{N}, 109^{\circ} \mathrm{E}\right)($ Kovalam et al., 1999).

Figure 3 shows the comparison of monthly mean zonal wind at $86 \mathrm{~km}$ over Tirunelveli (top panel) and radiosonde winds at $30 \mathrm{hPa}$ over Singapore (bottom panel). The longperiod oscillation in zonal wind at $86 \mathrm{~km}$ (shown as continuous curve) obtained by band-pass filtering (22-35 months) its monthly mean values is also plotted in the bottom panel. In Fig. 3 it is evident that the mesospheric QBO is nearly out of phase with the stratospheric QBO signature during the years 1993-98. However, it may be noted that this kind of anticorrelation is comparatively weaker during later years (1999-2001), the causes of which are yet to be examined.

The possible association of the activity of planetary-scale waves with the direction of stratospheric QBO winds is next investigated. Figures 4-7 show the comparison of the stratospheric QBO phase at $30 \mathrm{hPa}$ (bottom panel in all figures) and time-variance of 2-d wave (Fig. 4), 6.5-d wave (Fig. 5), 16-d wave (Fig. 6) and 3.5-d wave (Fig. 7) in zonal wind at $86 \mathrm{~km}$ (top panels) for the years 1993-1997, presented in the area-preserving variance content form. The data for the years 1998 to 2001 are not considered, as the percentage of data acceptance during these years is relatively smaller and it may cause greater uncertainties in the estimation of planetary wave characteristics.

Most observations in the southern and northern hemispheres generally suggest that the 2-d wave is consistent with a westward propagating wave of zonal wavenumber 3 (for example, Muller and Nelson, 1978; Craig et al., 1980). On the other hand, zonal wavenumbers between 2 and 5 were also reported in the literature (Clark et al., 1993; Cevolani et al., 1983; Meek et al., 1996). The mechanism by which the 2 -d wave is generated remains uncertain. It has been reported in the past that the 2-d wave could be generated in-situ as an unstable mode probably arising from the instability processes at stratopause/lower mesospheric jets at midlatitudes (Plumb, 1983; Pfister, 1985; Salby and Callaghan, 2001). Stability analysis presented in these reports shows peaks of unstable wave growth at zonal wavenumbers $2-4$ with periods $1.5-3$ days. The baroclinic instability occurs only at limited times of the year when the summer stratopause jet has its greatest curvature. The presence of 2-d wave observed in radar measurements almost throughout the year precludes the baroclinic instability hypothesis. An alternating generating mechanism was proposed by Salby (1981a) who suggested that the wave is a manifestation of the $(3,0)$ atmospheric normal mode driven by "noise" at lower levels. Since identification of the generating mechanism of the 2-d wave and its wavenumber characteristics remain unresolved 

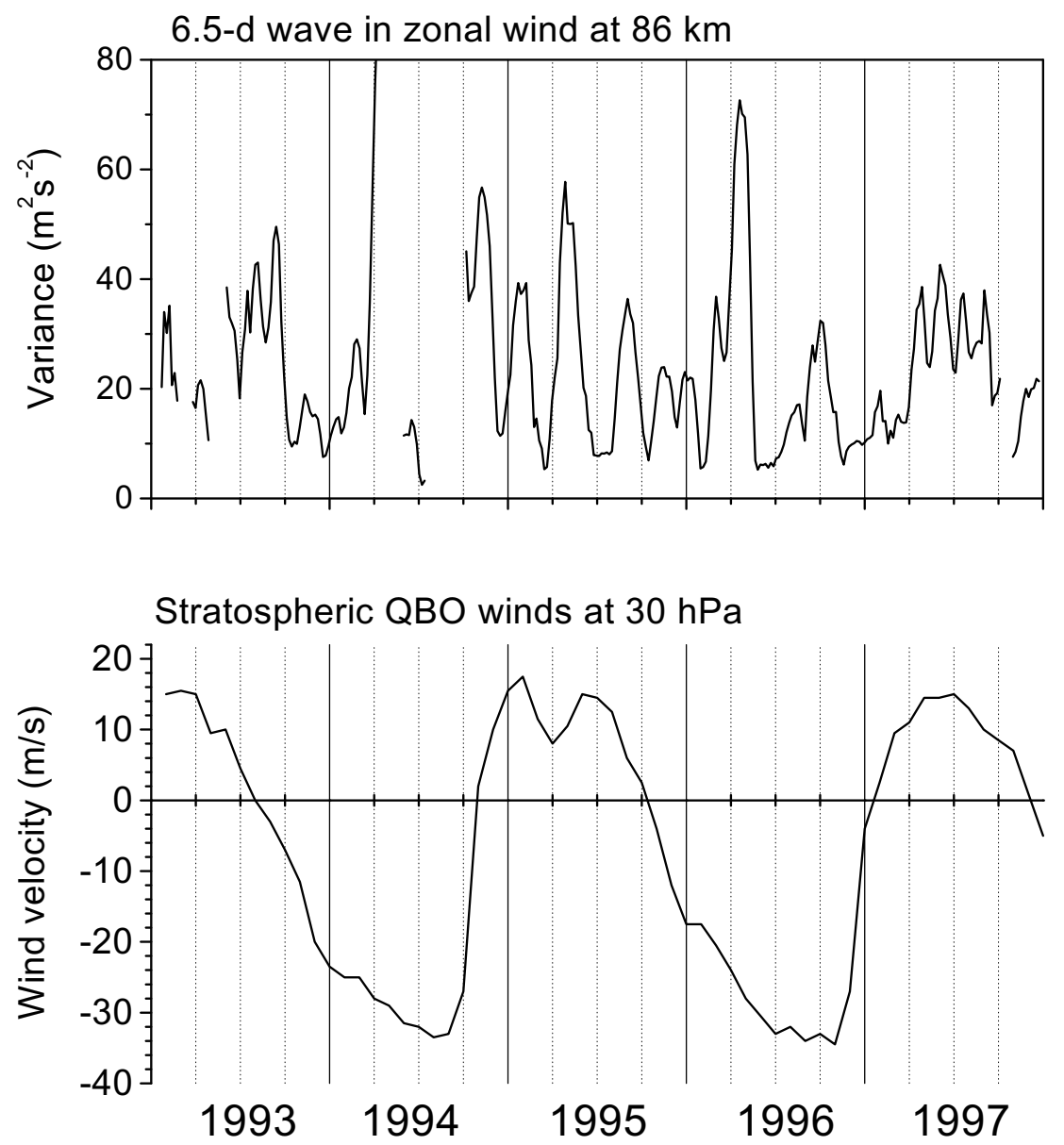

Fig. 5. Same as Fig. 4 but for 6.5 -day wave.

issues, for the purpose of the present analysis we may as well presume that the waves reach the MLT heights from below and are of zonal wavenumbers $2-5$.

From Fig. 4, it can be inferred that more active periods of the 2-d wave occur during mid-1993 and early 1995 when the stratospheric QBO winds are weakly eastward. The low wave active periods of 2-d wave during the years 1994 and 1996 coincide with the peak westward flow of stratospheric winds. From the relation $C_{p}=\omega / k$, the phase speeds for zonal wavenumbers 2 to 5 for the 2 -d wave are calculated to be $\sim 120 \mathrm{~m} / \mathrm{s}, \sim 70 \mathrm{~m} / \mathrm{s}, \sim 50 \mathrm{~m} / \mathrm{s}$, and $\sim 40 \mathrm{~m} / \mathrm{s}$, respectively. The phase speeds of 2-d wave of zonal wavenumber 5 are comparable to the mean wind speeds (maximum of $35 \mathrm{~m} / \mathrm{s}$ at $30 \mathrm{hPa}$ ) associated with the westward phase of the stratospheric QBO. Hence, waves of latter wavenumber may encounter critical region when the background wind velocity is westward and its magnitude is comparable to the phase speed of the waves (for example, during the years 1994 and 1996). When the underlying winds are eastward (for example, during the years 1993, 1995 and 1997), westward propagating waves of all zonal wavenumbers will not encounter critical regions and hence propagate through them with little damping. During July 1993, peak wave activity is observed when the QBO wind at $30 \mathrm{hPa}$ undergoes transition from eastward to westward phase, a situation still favourable for the propagation of 2-d waves. The 2-d wave peak observed during January 1995 occurs during the eastward phase of the strato- spheric QBO at $30 \mathrm{hPa}$. It may be noticed that the spectral variances for 1997 (July) are smaller when compared to the other strong active levels observed during 1993 (July) and 1995 (January). The stratospheric QBO is in the eastward phase at this time (July 1997). The observed lower activity may be associated with the temporal variability of the wave excitation mechanism.

Though the 2-d wave is a summer phenomenon, observations indicate that they may appear during equinoxes also (for example, during September-October 1995 in the present work) (Thayaparan et al., 1997, for other work). It may be noted that the background wind at MLT heights has large westward speeds during these MSAO equinox regimes. From the estimated phase speeds associated with lower wavenumbers 2,3 and $4(\sim 120,70$ and $50 \mathrm{~m} / \mathrm{s} \mathrm{respec-}$ tively) and the observed mean wind speeds $(\sim 50-80 \mathrm{~m} / \mathrm{s})$ at MLT heights, we may expect that the observed waves during equinoxes would be of the lower zonal wavenumber 2 . Observations from widely spaced stations are required to confirm this feature. During solstice seasons, however, the 2$\mathrm{d}$ wave can propagate through the mesospheric heights, as the wind direction at MLT heights during solstices is mainly eastward.

Radar and satellite observations show that the 6.5-d wave is a westward propagating wave of zonal wavenumber 1 (Kovalam et al., 1999; Talaat et al., 2001). It was proposed to be generated by forcing due to high-latitude baroclinic 

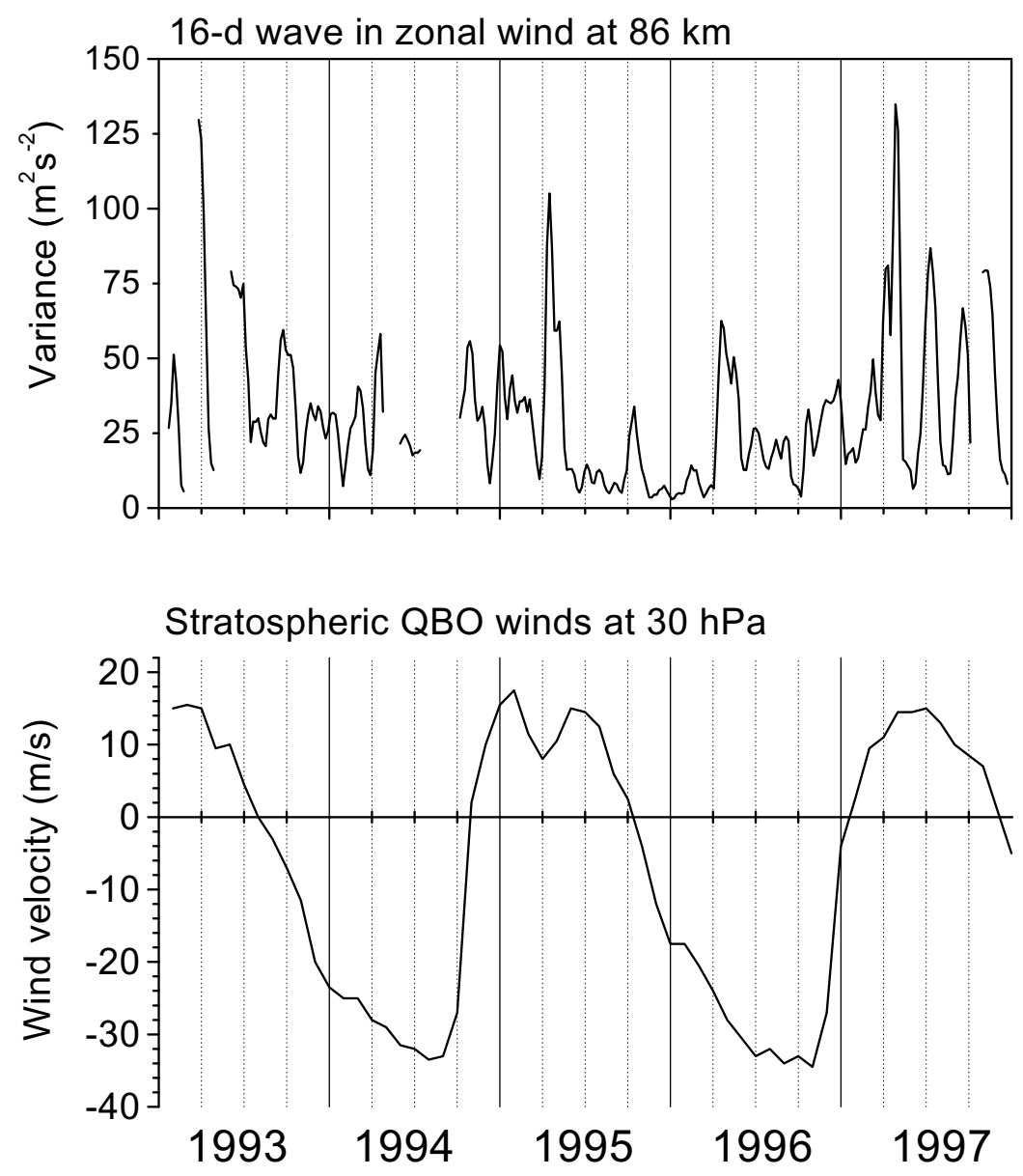

Fig. 6. Same as Fig. 4 but for 16-day wave.

instability (Meyer and Forbes, 1997). However, Talaat et al. (2001) found little mid- or high-latitude structure in the zonal wind amplitude in the UARS-HRDI data sets. It is suggested that in-situ forcing is not occurring at least in the altitude region sampled by HRDI $(50-115 \mathrm{~km})$. As with the case of the 2-day wave, it is presumed in the present analysis that the 6.5-d wave is generated in the lower atmosphere and propagates through the stratosphere to the MLT region.

Figure 6 shows the same as Fig. 5 but for 6.5 -d wave. The 6.5-d wave activity is observed to be larger with variance greater than $70 \mathrm{~m}^{2} \mathrm{~s}^{-2}$ during April 1994 and April 1996, when stratospheric winds are westward. These peaks in wave activity occur when mesospheric zonal wind is weakly westward (see Fig. 3). The wave variance is comparatively less $\left(50 \mathrm{~m}^{2} \mathrm{~s}^{-2}\right.$ ) during April 1993, 1995 and 1997, when stratospheric winds are westward. Since the 6.5 -d wave is believed to be a westward-propagating wave, it would undergo critical level absorption at stratospheric heights, if it had velocity nearly equal to the stratospheric westward wind speed $(\sim 35 \mathrm{~m} / \mathrm{s})$. Observational evidences have shown that the 6.5-d wave is, in general, found to have zonal wavenumber 1 (Kovalam et al., 1999). The phase speed of the 6.5-d wave is computed to be $\sim 65 \mathrm{~m} / \mathrm{s}$ for zonal wavenumber 1 . This being greater than the stratospheric QBO wind speeds $(\sim 35$ $\mathrm{m} / \mathrm{s})$, it is inferred that this wave would reach mesospheric heights.

The variability of MLT mean winds needs to be exam- ined in order to explain the presence of these waves at these heights. Since the mesospheric mean westward winds are sufficiently strong during the equinox months of the years 1993, 1995 and $1997(50-80 \mathrm{~m} / \mathrm{s})$ and the wind speed has become comparable to the phase speed of the wave, the wave might have undergone absorption at mesospheric heights. Though the stratospheric winds are westward during the years 1994 and 1996, the phase velocity of the wave is much greater than the QBO wind speeds and hence the wave can reach mesospheric heights conveniently. The wave may reach even greater heights, as mesospheric winds are not so strong in the years 1994 and 1996.

The secondary maxima in wave activity are observed during July-September 1993 and 1997, January-February 1995, July-August 1997. These periods coincide with either eastward mesospheric SAO or change of SAO phase from eastward to westward.

Miyoshi (1999) based on the results obtained with the numerical simulation of 16-d wave found that the wave is mainly excited by heating due to the moist convection in the troposphere. The wave then penetrates into the middle atmosphere. In this scenario, let us consider now the possible influence of stratospheric QBO winds on the vertical propagation of 16-d wave in zonal wind.

Figure 7 shows the same as Fig. 5 but for 16-d wave. The comparison of 16-d wave activity with stratospheric winds shows that the $16-\mathrm{d}$ wave is more active with vari- 

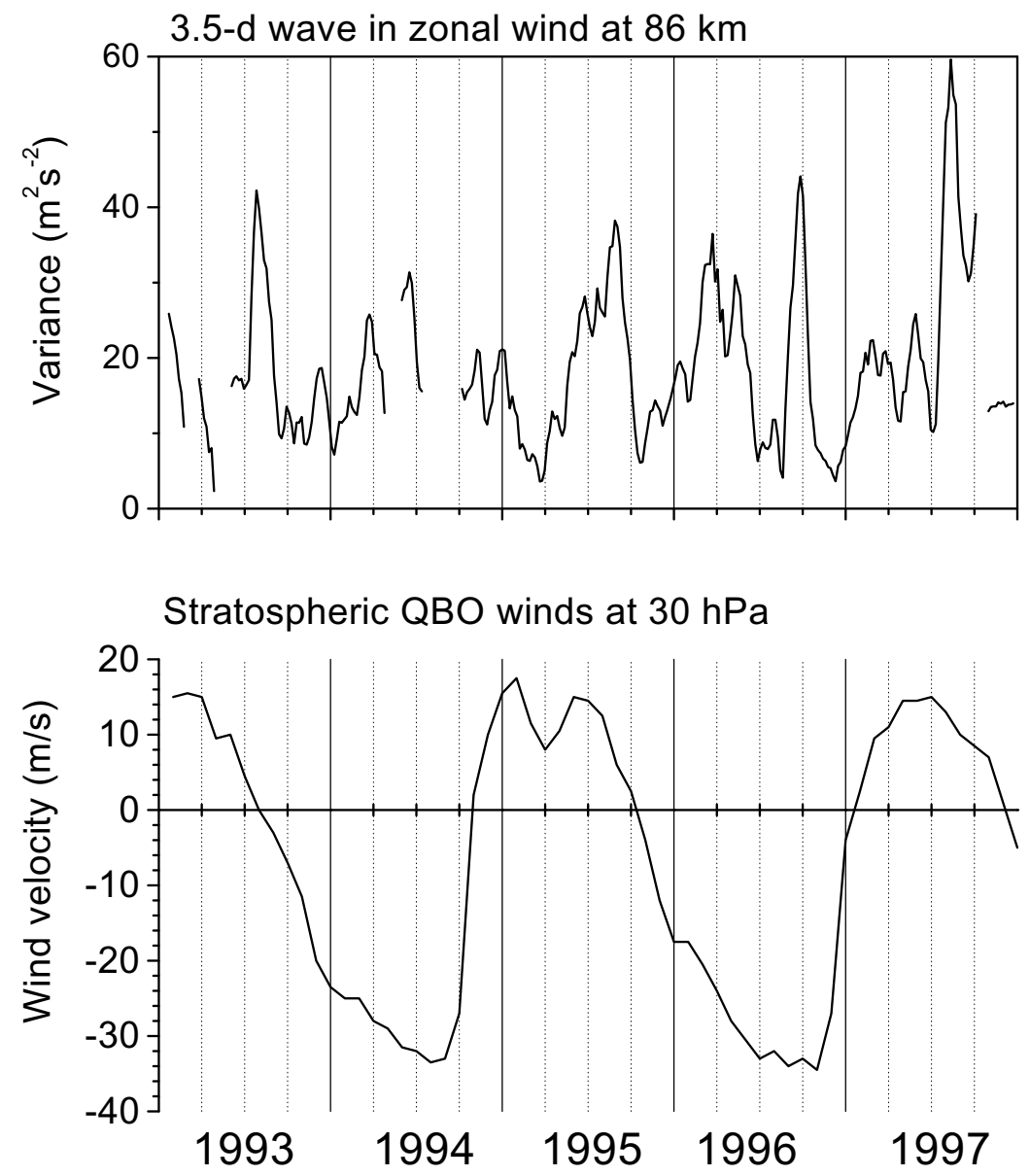

Fig. 7. Same as Fig. 4 but for 3.5-day wave.

ances greater than $100 \mathrm{~m}^{2} \mathrm{~s}^{-2}$ during spring equinox months (March-April) of 1993, 1995 and 1997, when the stratospheric QBO winds are eastward. The wave has smaller energy during those months of the years, 1994 and 1996, with variances less than $60 \mathrm{~m}^{2} \mathrm{~s}^{-2}$, when the underlying winds are westward. The phase velocity for the 16-d wave with zonal wavenumber 1 is $\sim 30 \mathrm{~m} / \mathrm{s}$ from the known wavenumber-phase velocity relationship. This is comparable to the maximum westward stratospheric QBO wind speed. As the wave is westward propagating, it may undergo critical level absorption at stratospheric heights during the years 1994 and 1996, when the stratospheric QBO is in westward phase. During the years 1993, 1995 and 1997, when the stratospheric QBO is in eastward phase, the condition is favourable for its direct vertical propagation.

Though stratospheric winds are favourable for the westward propagating 16-d wave at certain times, the wave may undergo significant damping while propagating through the mesospheric westward winds. However, the presence of these waves at MLT heights during these periods (for example, during the spring months of 1993, 1995 and 1997) suggests that the waves would have been generated in situ at these heights due to the momentum deposition by gravity waves that could be modulated at 16-d periods at lower heights (Williams and Avery, 1992).

The interannual variability of the 16-d wave has been addressed earlier by Espy et al. (1997) and Jacobi et al. (1998a, b). Espy et al. (1997) found 16-d wave in polar mesopause temperatures. The authors gave an explanation for its presence in summer in terms of cross-equator propagation and the modulation effects induced by the QBO. It should be noted that in the modeling study of Forbes et al. (1995) the cross-equator propagation occurs in upper mesopause heights and so should be largely unaffected by the stratospheric QBO.

Luo et al. (2000) studied interannual variability of 16-d wave over Saskatoon $\left(52^{\circ} \mathrm{N}, 107^{\circ} \mathrm{W}\right)$ using nearly 16 years of MF radar data, in terms of winter and summer events, considering respectively, the effect of stratospheric warming in the winter polar stratosphere and hemispheric leakage. They found no evidence for the relation between the local winter 16-d waves and major stratospheric warmings. However, they found positive/negative/weak correlation between the stratospheric QBO and 16-d wave amplitudes at mesospheric heights. They observed that the 16-d wave preferred to appear during the westward QBO phase at certain times. The present study reveals consistent occurrence of 1arge amplitude 16-d wave during eastward phase of stratospheric QBO. However, the number of years considered herein is very limited.

Figure 8 shows the same as Fig. 5 but for the 3.5-d ultrafast Kelvin (UFK) wave. The comparison of 3.5-d wave activity with the direction of stratospheric QBO winds shows that the wave is present irrespective of whether the strato- 
spheric QBO winds are eastward or westward. The phase speed of the 3.5-d wave for zonal wavenumber 1 is $\sim 120$ $\mathrm{m} / \mathrm{s}$ and is sufficiently larger than the QBO wind speed and hence it can easily reach the mesospheric heights. Comparison of Fig. 8 with the top panel of Fig. 3 shows that the 3.5-d wave energy tends to appear preferentially during the westward phase of the mesospheric SAO. This has been reported earlier by the authors (Sridharan et al., 2002). Yoshida et al. (1999) have observed a similar behaviour of the UFK wave over Indonesia. Peaks during September 1995, March 1996, October 1996 and September 1997 coincide with the peak westward zonal flow. It is anticipated that as the 3.5-d UFK is an eastward propagating wave, westward zonal flow is a favourable condition for its vertical propagation. However, it may also be noted that the observed Kelvin wave amplitudes are relatively smaller at times of intense mean westward motions (in the range $50-80 \mathrm{~m} / \mathrm{s}$ ) in the zonal flow, for example, during the spring months of 1995 and 1997.

\section{Conclusion}

It is known that the long-term variability of planetary waves is mainly governed by the underlying winds through which they propagate and the strength and efficiency of the wave excitation processes at various levels. In this paper, the interannual variability of planetary-scale waves is examined based on the direction of stratospheric QBO at $30 \mathrm{hPa}$ level. The presence of these waves at MLT heights over interannual time scales can be explained partly by considering an appropriate phase of the stratospheric QBO. One limitation of this work is that the number of QBO cycles considered is too few. Also, there are some observations which cannot be explained based on the direction of the stratospheric QBO wind speed alone.

It has not been possible so far to ascertain whether the observed long-period waves in the MLT region owe their origin to the instabilities driven in-situ or propagate from below. The observational knowledge of source mechanisms responsible for the generation of planetary waves has been very limited and any future study in this direction will help to resolve some of the issues raised in this work.

\section{References}

Andrews, D. G., J. R. Holton, and C. B. Leovy, Middle Atmosphere Dynamics, 489 pp., Academic Press, 1987.

Burrage, M. D., R. A. Vincent, H. G. Mayr, W. R. Skinner, N. F. Arnold, and P. B. Hays, Long-term variability in the equatorial mesosphere and lower thermosphere zonal winds, J. Geophys. Res., 101, 12847-12854, 1996.

Cevolani, G., S. P. Kingsley, and G. Muller, Three-station meteor wind observations in northern Europe during summer 1980, J. Atmos. Terr. Phys., 45, 275-280, 1983.

Clark, R. R., A. C. Current, A. H. Manson, C. E. Meek, S. K. Avery, S. E. Palo, and T. Aso, Global properties of the 2-day wave from mesospherelower thermosphere radar observations, J. Atmos. Terr. Phys., 43, 12791288, 1993

Craig, R. L., R. A. Vincent, G. J. Fraser, and M. J. Smith, The quasi 2 day wave near $90 \mathrm{~km}$ altitude at Adelaide ( $\left.35^{\circ} \mathrm{S}\right)$, Nature, 287, 319-322, 1980.

Dunkerton, T. J., Theory of the mesopause semiannual oscillation, J. Atmos. Sci., 39, 2681-2690, 1982.

Dunkerton, T. J., The role of gravity waves in the quasi-biennial oscillation, J. Geophys. Res., 102, 26053-26076, 1997.

Espy, P. J., J. Stregmann, and G. Witt, Interannual variation of the quasi-16day oscillation in the polar summer mesospheric temperature, J. Geophys. Res., 102(2), 1983-1990, 1997.
Forbes, J. M., M. E. Hagan, S. Miyahara, F. Vial, A. H. Manson, C. E. Meek, and Y. Portnyagin, Quasi 16-day oscillation in the mesosphere and lower thermosphere, J. Geophys. Res., 100, 9149-9163, 1995.

Garcia, R. R. and F. Sassi, Modulation of the mesospheric semiannual oscillation by the quasibiennial oscillation, Earth Planets Space, 51, 563 $569,1999$.

Garcia, R. R., T. J. Dunkerton, R. S. Lieberman, and R. A. Vincent, Climatology of the semiannual oscillation of the tropical middle atmosphere, $J$. Geophys. Res., 102, 26019-26032, 1997.

Gurubaran, S. and R. Rajaram, Long-term variability in the mesospheric tidal winds observed by MF radar over Tirunelveli $\left(8.7^{\circ} \mathrm{N}, 77.8^{\circ} \mathrm{E}\right), \mathrm{Geo}$ phy. Res. Lett., 26(8), 1113-1116, 1999.

Gurubaran, S., S. Sridharan, T. K. Ramkumar, and R. Rajaram, The mesospheric quasi-2-day wave over Tirunelveli $\left(8.7^{\circ} \mathrm{N}\right)$, J. Atmos. Solar-Terr Phys., 63, 975-985, 2001.

Hagan, M. E., M. E. Burrage, J. M. Forbes, J. Hackney, W. J. Randel, and X. Zhang, GSWM-98: Results for migrating solar tides, J. Geophys. Res., 104, 6813-6828, 1999.

Hamilton, K. P., Rocketsonde observations of the mesospheric semiannual oscillation at Kwajalein, Atmos-oceans, 20, 281-286, 1982.

Harris, T. J., A long-term study of the quasi 2-day wave in the middle atmosphere, J. Atmos. Terr. Phys., 56(5), 569-579, 1994.

Hirota, I., Equatorial waves in the upper stratosphere and mesosphere in relation to the semiannual oscillation of the zonal mean wind, J. Atmos Sci., 35, 714-722, 1978 .

Holton, J. R. and R. S. Lindzen, An updated theory for the quasi-biennial cycle of the tropical stratosphere, J. Atmos. Sci., 29, 1076-1080, 1972.

Jacobi, Ch., R. Schminder, and D. Kurschner, Planetary wave activity obtained from long-period (2-18 days) variations of mesopause region winds over Central Europe $\left(52^{\circ} \mathrm{N}, 15^{\circ} \mathrm{E}\right)$, J. Atmos. Sol.-Terr. Phys., 60 81-93, 1998a.

Jacobi, Ch., R. Schminder, and D. Kurschner, Long-period (12-25 days) oscillations in the summer mesopause region as measured at Collm $\left(52^{\circ} \mathrm{N}\right.$, $15^{\circ} \mathrm{E}$ ) and their dependence on the equatorial quasi-biennial oscillation, Contrib. Atmos. Phys., 71, 461-464, 1998b.

Kovalam, S., R. A. Vincent, I. M. Reid, T. Tsuda, T. Nakamura, K. Ohnishi, A. Nuryanto, and H. Wiryosumarto, Longitudinal variations in planetary wave activity in the equatorial mesosphere, Earth Planets Space, 51, 665674, 1999.

Luo, Yi., A. H. Manson, C. E. Meek, C. K. Meyer, and J. M. Forbes, The quasi 16-day oscillations in the mesosphere and lower thermosphere at Saskatoon $\left(52^{\circ} \mathrm{N}, 107^{\circ} \mathrm{W}\right), 1980-1996$, J. Geophys. Res., 105, 2125 2138, 2000.

Manson, A. H. and C. E. Meek, Atmospheric waves (10 min-30 days) in the mesosphere and thermosphere at saskatoon $(52 \mathrm{~N}, 107 \mathrm{~W})$ : A spectral study during 1981, 1982, J. Atmos. Terr. Phys., 48, 1039-1055, 1986.

Mayr, H. G., J. G. Menger, C. O. Hines, K. L. Chan, N. F. Arnold, C. A Reddy, and H. S. Porter, The gravity wave Doppler spread theory applied in a numerical spectral model of the middle atmosphere, 2. Equatorial oscillations, J. Geophys. Res., 102, 26093-26238, 1997.

Meek, C. E., A. H. Manson, S. J. Franke, W. Singer, P. Hoffmann, R. R. Clark, T. Tsuda, T. Nakamura, M. Tsutsumi, M. Hagan, D. C. Fritts, J Ishu, and Yu I. Portnyagin, Global study of northern hemisphere quasi 2-day wave events in recent summers near $90 \mathrm{~km}$ altitude, J. Atmos. Terr Phys., 58, 1401-1411, 1996.

Meyer, C. K. and J. M. Forbes, A 6.5-day westward propagating planetary wave: origin and its characteristics, J. Geophys. Res., 102, 26173-26178, 1997.

Miyoshi, Y., Numerical simulation of the 5-day and 16-day waves in the mesopause region, Earth Planets Space, 51, 763-772, 1999.

Muller, H. G. and L. Nelson, A travelling quasi-2-day in the meteor region, J. Atmos. Terr. Phys., 40, 761-766, 1978.

Palo, S. E., M. E. Hagan, C. E. Meek, R. A. Vincent, M. D. Burrage, C. McLandress, S. J. Franke, W. E. Ward, R. R. Clark, P. Hoffmann, R. Johnson, D. Kurschner, A. H. Manson, D. Murphy, T. Nakamura, Yu I. Portnyagin, J. E. Salah, R. Schminder, W. Singer, T. Tsuda, T. S Virdi, and Q. Zhou, An intercomparison between the GSWM, UARS, and ground based radar observations: A case-study in January 1993, Ann Geophys., 15, 1123-1141, 1997.

Plumb, R. A., Baroclinic instability of the summer mesosphere: A mechanism for the quasi-two-day wave?, J. Atmos. Sci., 40, 262-270, 1983.

Plumb, R. A. and A. D. McEwan, The instability of a forced standing wave in a viscous stratified fluid: A laboratory analogue of the quasi-biennial oscillation, J. Atmos. Sci., 35, 1827-1839, 1978.

Pfister, L., Baroclinic instability of easterly jets with applications to the 
summer mesosphere, J. Atmos. Sci., 42, 313-330, 1985.

Press, W. H., S. A. Teukolsky, W. T. Vetterling, and B. P. Flannery, Numerical Recipes in Fortran 77, second edition-the Art of Scientific Computing, Cambridge University Press, Cambridge, 1992.

Rajaram, R. and S. Gurubaran, Seasonal variabilities of low-latitude mesospheric winds, Ann. Geophys., 16, 197-204, 1998.

Salby, M. L., Rossby normal modes in nonuniform background configurations, Part I: Simple fields, J. Atmos. Sci., 28, 1803-1826, 1981a.

Salby, M. L., Rossby normal modes in nonuniform background configurations, Part II: Equinox and solstice conditions, J. Atmos. Sci., 38, $1827-$ 1840, 1981b.

Salby, M. L. and P. F. Callaghan, Seasonal amplification of the 2-day wave: Relationship between normal mode and instability, J. Atmos. Sci., 58, 1858-1869, 2001

Sridharan, S., S. Gurubaran, and R. Rajaram, Radar observations of the 3.5 day Ultra-fast Kelvin wave in the low latitude mesopuase region, $J$ Atmos. Sol.-Terr. Phys., 64, 1241-1250, 2002.

Talaat, E. R., J.-H. Yee, and X. Zhu, Observations of the 6.5-day wave in the mesosphere and lower thermosphere, J. Geophys. Res., 106, 20715 20723, 2001.

Thayaparan, T., W. K. Hocking, and J. MacDougall, Amplitude, phase, and period variations of the quasi 2-day wave in the mesosphere and lower thermosphere over London, Canada $\left(43^{\circ} \mathrm{N}, 81^{\circ} \mathrm{W}\right)$, during 1993 and 1994, J. Geophys. Res., 102(D8), 9461-9478, 1997.

Tsuda, T., S. Fukao, M. Yamamoto, T. Nakamura, M. D. Yamanaka, T. Adachi, H. Hashiguchi, N. Fujioka, M. Tsutsumi, S. Kato, S. W. B. Harijono, T. Sribimawati, B. P. Sitorus, R. B. Yahya, M. Karmini, F. Reng- gono, B. L. Parapat, W. Djojonegoro, P. Mardio, N. Adikusumah, H. T. Endi, and H. Wiryosumarto, A preliminary report on observations of equatorial atmosphere dynamics in Indonesia with radars and radiosondes, J. Meteorol. Soc. Jpn., 73, 393-406, 1995.

Vincent, R. A., Long-period motions in the equatorial middle atmosphere, J. atmos. Terr. Phys., 55, 1067, 1993.

Vincent, R. A. and D. Lesicar, Dynamics of the equatorial mesosphere: first results with a new generation partial reflection radar, Geophys. Res. Lett. 18, 825-828, 1991.

Vincent, R. A., S. Kovalam, D. C. Fritts, and J. R. Isler, Long-term MF radar observations of solar tides in the low-latitude mesosphere: Interannual variability and comparisons with GSWM, J. Geophys. Res., 103, 86678683, 1998.

Wallace, J. M. and V. E. Kousky, Observational evidence of Kelvin waves in the tropical stratosphere, J. Atmos. Sci., 25, 900-907, 1968.

Williams, C. R. and S. K. Avery, Analysis of long-period waves using the mesosphere-stratosphere-troposphere radar at Poker Flat, Alaska, J. Geophys. Res., 97, 20855-20861, 1992.

Yoshida, S., T. Tsuda, A. Shimizu, and T. Nakamura, Seasonal variations of 3.0 3.8-day ultra-fast Kelvin waves observed with a meteor radar and radiosonde in Indonesia, Earth Planets Space, 51, 675-684, 1999.

S. Sridharan (e-mail: ssri_dhar@rediffmail.com), S. Gurubaran (email: gurubara@md4.vsnl.net.in), and R. Rajaram (e-mail: rrajaram@iigs.iigm.res.in) 